\title{
Direct Torque Control of Induction Motors using Speed Estimator
}

\author{
${ }^{1}$ Kasoju Bharath Kumar ${ }^{2}$ Dr.P. Chandra Sekhar ${ }^{3}$ H. Gurunath \\ ${ }^{1}$ Assistant Professor, Department of EEE, Mahatma Gandhi Institute of Technology, India, \\ bharathchary15@gmail.com \\ ${ }^{2}$ Associate Professor, Department of EEE, Mahatma Gandhi Institute of Technology, India, \\ pchandrashekar_eee@mgit.ac.in \\ ${ }^{3}$ Assistant Professor, Department of EEE, Mahatma Gandhi Institute of Technology, India, \\ hgurunath_eee@mgit.ac.in
}

\begin{abstract}
A new approach to Direct torque control of induction motor is presented in this paper. A ripple in torque of the induction motor is a very common problem and it is to be reduced. In conventional DTC methods the inverter has constant switching frequency and is dramatically increased. In proposed DTC based induction motor drive, an improved space vector modulation technique is applied to inverter control, therefore reducing the torque/speed ripples. As the proposed approach does not include any dead beat control or hysteresis control, it automatically reduces computational calculations. Simulation results of proposed DTC based induction motor drive technique is validated using MATLAB/SIMULINK environment.
\end{abstract}

Key words: Direct torque control, induction motor drives, inverter, reduced torque ripples.

\section{INTRODUCTION}

Basically Induction motor torque can be controlled by scalar control and vector control. The scalar control can control speed but cannot improve dynamic response. To overcome this problem vector control technique is used in wide variety of applications. In Vector control techniques the most popular types are FOC (Field oriented Control) and DOC (Direct torque control). It is well known that in FOC Scheme involves control loops which control direct and quadrature axis currents. FOC scheme is also used to improve the characteristics of the motor to reduce the order of torque equation. FOC also involves tedious work when compared to DTC. Hence, Steady state response has better characteristics if FOC is used, Dynamic response is better is characteristics if DTC is used. Therefore DTC includes high torque ripples in steady state response. The direct torque control approach controls the stator flux and the Electromagnetic torque simultaneously using the hysteresis controllers and PI (Proportional Integral) blocks.
As demonstrated in [1], [3],[4],[5][6], both flux and torque of a DTC-based drive are controlled as closed loop control systems without using current loops as used in FOC methods. Moreover, the DTC-based drives do not require fulfilling the coordinate transformation between stationary frame and synchronous frame, in comparison with the conventional vector-controlled drives (FOC). Since a DTC-based drive[1], selects the inverter switching states using look up tables, it does not require any current controllers nor pulse-width modulation (PWM) modulators, and hence providing fast torque response [2] . But this switching-table-based DTC approach also have some disadvantages; more details are described as follows.

For digital implementation, the system sampling frequency for the calculations of torque and flux should be very fast in order to provide good tracking performance and limit the errors of torque and flux within the specified bands,

respectively.Theinverterswitchingfrequency, whichvaries withspeedofdrivesand the associated error bands, is very low in comparison with the system sampling frequency; a sampling frequency of $40 \mathrm{kHz}$ gives the inverter switching frequency about $3 \mathrm{kHz}$ as shown in[7]. Although the inverter switching frequency can be increased by mixing high frequency dither signals with the error signals of torque and flux [11], respectively, the inverter switching frequency is not constant for small error bands [8] and the difficulty of designing inverter output filter becomes difficult. For the DTC-based drives, the torque ripple is significantly for not invoking the zero inverter switching states; especially at motor start-up [9] or under transient state[10,12].

Normally, to provide constant inverter switching frequency, a space vector modulation (SVM) modulator is incorporated with direct torque control for induction motor drives as shown in[2],[11]. In [2], by considering several complicate calculations, a dead beat controller is used to generate the voltage command of SVM modulator which can be easily generated with high end Microprocessors. 
In[13], a predictive controlleris used to give the command to the inverter using space vector modulator. In these days Model Predictive control (MPC) technique is widely used in control of electrical drives as their concept is very simple.

\section{MODELING OF INDUCTION MACHINE:}

Dynamic model of Induction Machine:

The three Phase stator currents system with angular frequency $\mathrm{w}_{0}$ can be defined in a fixed three phase coordinate frame as

$$
\begin{aligned}
& I_{a}=I \sin \left(w_{0} t\right) \\
& I_{b}=I \sin \left(w_{0} t+2 * \pi / 3\right) \\
& I_{c}=I \sin \left(w_{0} t+4 * \pi / 3\right)
\end{aligned}
$$

The transformation from three phase to two phase systems for stator currents is described by

$$
I_{s}=2 / 3\left(i_{a}+a i_{b}+a^{2} i_{c}\right)
$$

Where $a=e^{j 2 \pi / 3}, a^{2}=e^{j 4 \pi / 3}$

The above transformation is used for Electromagnetic Variables as shown below:

Let the variable w denotes the rotor angular speed then,

$$
\begin{aligned}
& \mathrm{v}_{\mathrm{s}}=\mathrm{R}_{\mathrm{s}} * \mathrm{I}_{\mathrm{s}}+\mathrm{d} \psi_{\mathrm{s}} / \mathrm{dt}+\mathrm{j} \psi_{\mathrm{s}}{ }^{*} \mathrm{w}_{\mathrm{k}} \\
& 0=\mathrm{R}_{\mathrm{r}}^{*} \mathrm{I}_{\mathrm{r}}+\mathrm{d} \psi_{\mathrm{r}} / \mathrm{dt}+\mathrm{j} \psi_{\mathrm{r}} *\left(\mathrm{w}_{\mathrm{k}}-\mathrm{w}\right) \\
& \psi_{\mathrm{s}}=\mathrm{L}_{\mathrm{s}} \mathrm{i}_{\mathrm{s}}+\mathrm{L}_{\mathrm{m}} * \mathrm{i}_{\mathrm{r}} \\
& \psi_{\mathrm{r}}=\mathrm{L}_{\mathrm{m}} \mathrm{i}_{\mathrm{s}}+\mathrm{L}_{\mathrm{r}} * \mathrm{i}_{\mathrm{r}} \\
& \mathrm{T}=3 / 2 \mathrm{p} \operatorname{Re}\left\{\psi_{\mathrm{s}} \mathrm{i}_{\mathrm{s}}\right\}=-3 / 2 \mathrm{p} \operatorname{Re}\left\{\psi_{\mathrm{r}} \mathrm{i}_{\mathrm{r}}\right\}
\end{aligned}
$$

Where $\mathrm{L}_{\mathrm{s}}, \mathrm{L}_{\mathrm{r}}$ and $\mathrm{L}_{\mathrm{m}}$ are stator, rotor and magnetizing inductances respectively.

$R_{s}$ and $R_{r}$ are stator and rotor resistances

$\mathrm{v}_{\mathrm{s}}$ and $\mathrm{i}_{\mathrm{s}}$ are stator voltage and current vectors.

$\mathrm{P}$ is number of pole pairs.

Electrical system equations:

$$
\begin{aligned}
& \mathrm{V}_{\mathrm{s}}=\mathrm{R}_{\mathrm{s}} \mathrm{i}_{\mathrm{s}}+1 / \mathrm{w}_{0}\left(\mathrm{df} \mathrm{f}_{\mathrm{s}} / \mathrm{dt}\right)+\mathrm{w}_{\mathrm{k}} \mathrm{M}(\mathrm{pi} / 2) * \mathrm{f}_{\mathrm{s}} \\
& \mathrm{V}_{\mathrm{r}}=\mathrm{R}_{\mathrm{r}} \mathrm{i}_{\mathrm{r}}+1 / \mathrm{w}_{0}\left(\mathrm{df}_{\mathrm{r}} / \mathrm{dt}\right)+\left(\mathrm{w}_{\mathrm{k}}-\mathrm{w}_{\mathrm{m}}\right) \mathrm{M}(\mathrm{pi} / 2) \mathrm{f}_{\mathrm{r}}
\end{aligned}
$$

where the variables $i, v$, and $f$ are 2-dimensional space vectors; $\mathrm{w}_{\mathrm{k}}$ is the speed of the reference frame, $\mathrm{w}_{\mathrm{m}}$ the rotor speed, and $\mathrm{M}(\mathrm{pi} / 2)$ represents a $90^{\circ}$ space rotator namely $\mathrm{M}(\mathrm{pi} / 2)$ $=[0-1 ; 10]$

The flux linkage current relations are:

$$
\begin{aligned}
& \mathrm{F}_{\mathrm{ds}}=\mathrm{L}_{\mathrm{s}} \mathrm{i}_{\mathrm{ds}}+\mathrm{L}_{\mathrm{m}} \mathrm{i}_{\mathrm{dr}} \\
& \mathrm{F}_{\mathrm{dr}}=\mathrm{L}_{\mathrm{m}} \mathrm{i}_{\mathrm{ds}}+\mathrm{L}_{\mathrm{r}} \mathrm{i}_{\mathrm{dr}} \\
& \mathrm{L}_{\mathrm{s}}=\mathrm{L}_{\mathrm{m}}+\mathrm{L}_{\mathrm{sl}} ; \mathrm{L}_{\mathrm{r}}=\mathrm{L}_{\mathrm{m}}+\mathrm{L}_{\mathrm{rl}} \\
& \mathrm{F}_{\mathrm{qs}}=\mathrm{L}_{\mathrm{s}} \mathrm{i}_{\mathrm{qs}}+\mathrm{L}_{\mathrm{m}} \mathrm{i}_{\mathrm{qr}} \\
& \mathrm{F}_{\mathrm{qr}}=\mathrm{L}_{\mathrm{m}} \mathrm{i}_{\mathrm{qs}}+\mathrm{L}_{\mathrm{r}} \mathrm{i}_{\mathrm{qr}}
\end{aligned}
$$

Mechanical system equations:

$$
\mathrm{T}_{\mathrm{e}}=2 * \mathrm{H}\left(\mathrm{dw}_{\mathrm{m}} / \mathrm{dt}\right)+\mathrm{B}_{\mathrm{m}} \mathrm{W}_{\mathrm{m}}+\mathrm{T}_{1}
$$

Where,

$$
\begin{aligned}
& \quad T_{e}=f_{s} \times i_{s}=M(p i / 2) f_{s} \cdot i_{s}=f_{d s} i_{q s}-f_{q s} i_{d s} \\
& =f_{s} \times i_{s}=M(p i / 2) f_{s} \cdot i_{s} \\
& =i_{r} \times f_{r}
\end{aligned}
$$

Therefore, by using the above equations model of Induction machine is created in Simulink 9.3 as shown in figure 1.

Static model of Induction machine:

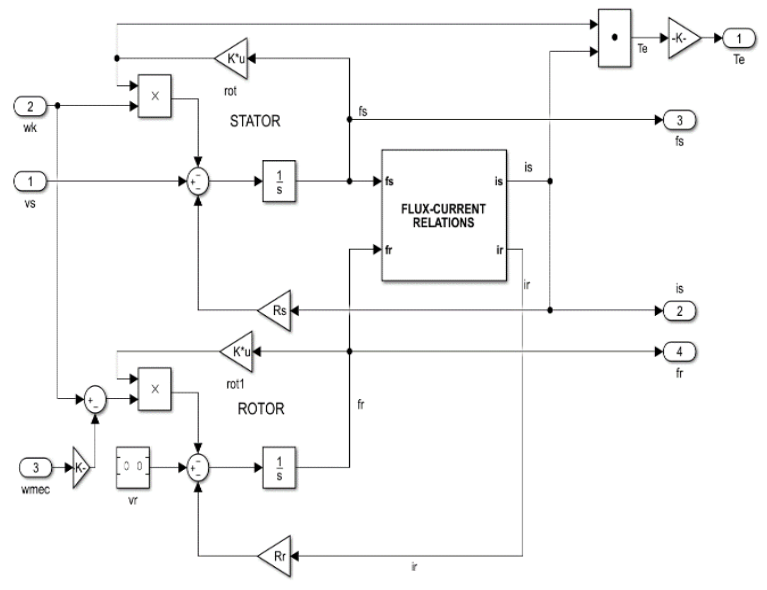

Figure 1: Induction Machine Model (Electrical) 


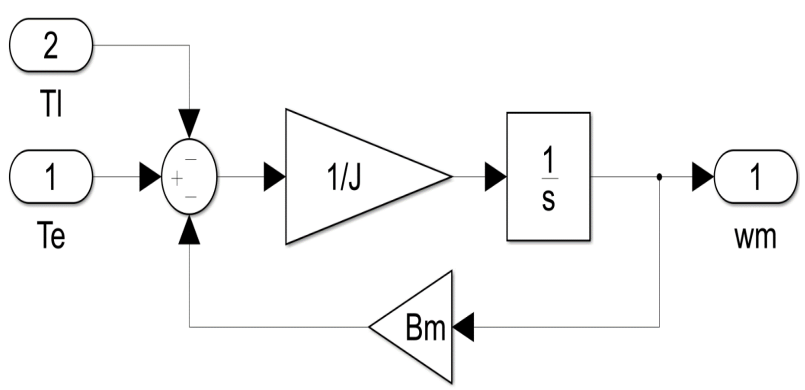

Figure 2: Induction Machine Model (Mechanical)

\section{PROPOSED CIRCUIT DIAGRAM:}

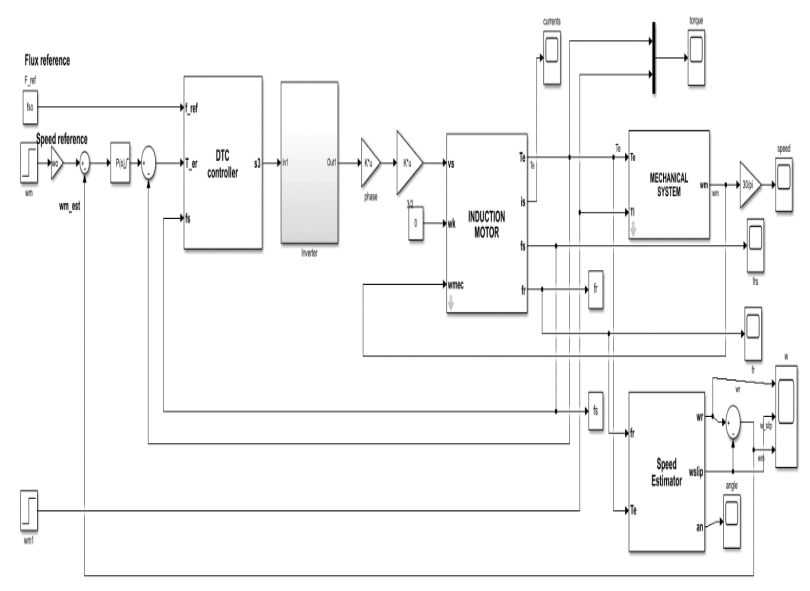

Figure 3: Direct Torque Control of Induction Machine Simulation Diagram

The proposed circuit is simulated in MATLAB Simulink 9.3 and the brief model is as shown in figure 3.

Referring to the figure 3, the DTC based drive has outer speed loop which is compared with the speed reference and fed to the PI controller to give the Torque error input to the DTC controller. DTC controller is the special type control in this paper which consists of hysteresis controllers and look up tables for sector selection.

There is a Speed Estimator to estimate the speed in terms of $\mathrm{f}_{\mathrm{r}}$ and $\mathrm{T}_{\mathrm{e}}$ and display the results.

The DTC Controller which is modelled in MATLAB Simulink 9.3 is shown in the figure 4 .

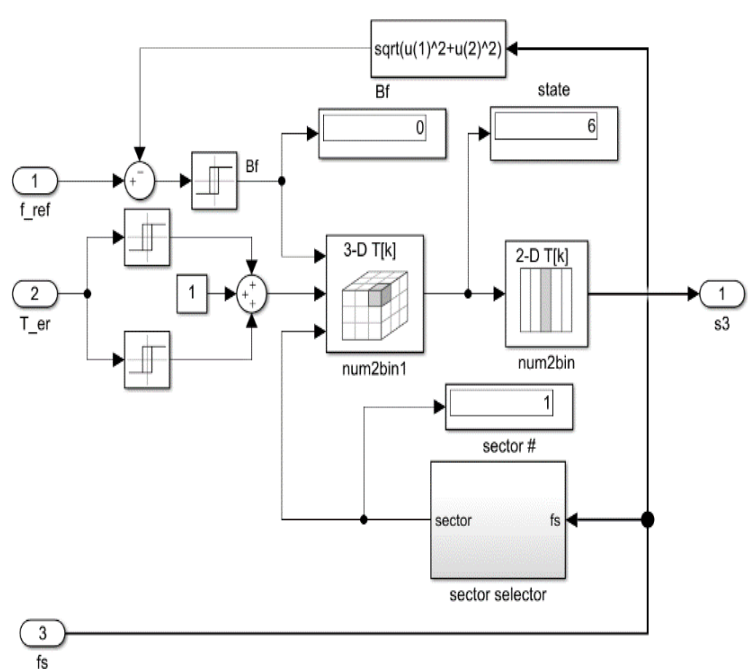

Figure 4 : DTC Controller Model

\section{SIMULATION RESULTS:}

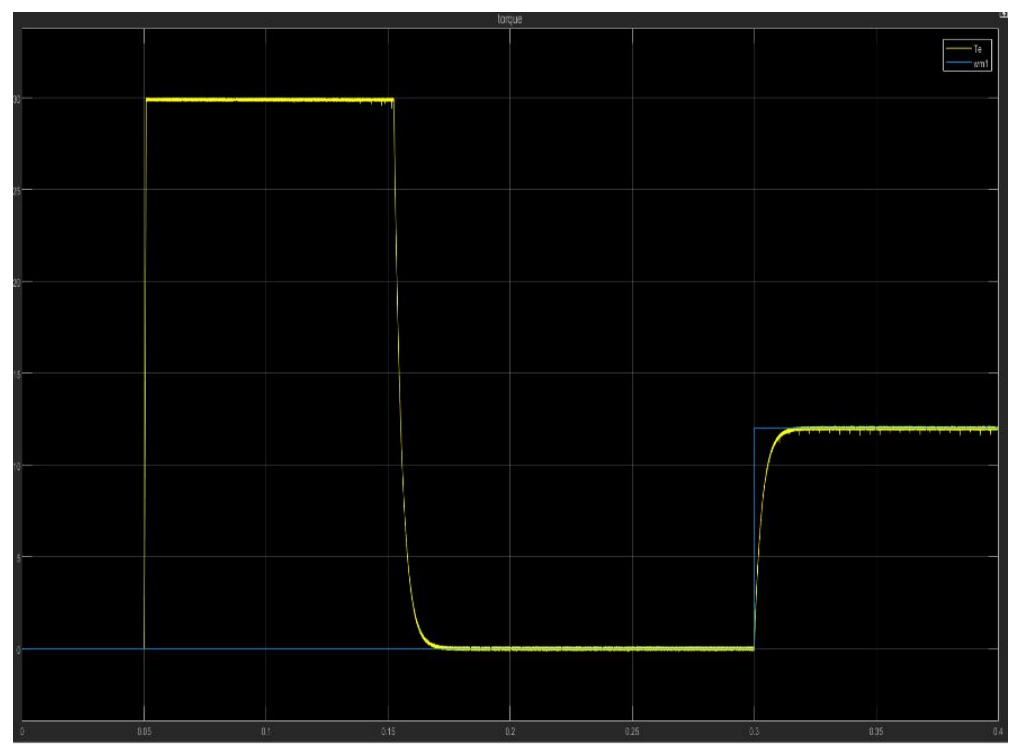

Figure 5: Torque and Speed of the Induction machine

The relation between torque and speed of induction machine is described in the mechanical system of machine model. Here, the speed is zero until the torque is zero at 0.3 seconds. At 0.3 seconds, the speed gets increased and settled down at constant speed as torque got increased. 


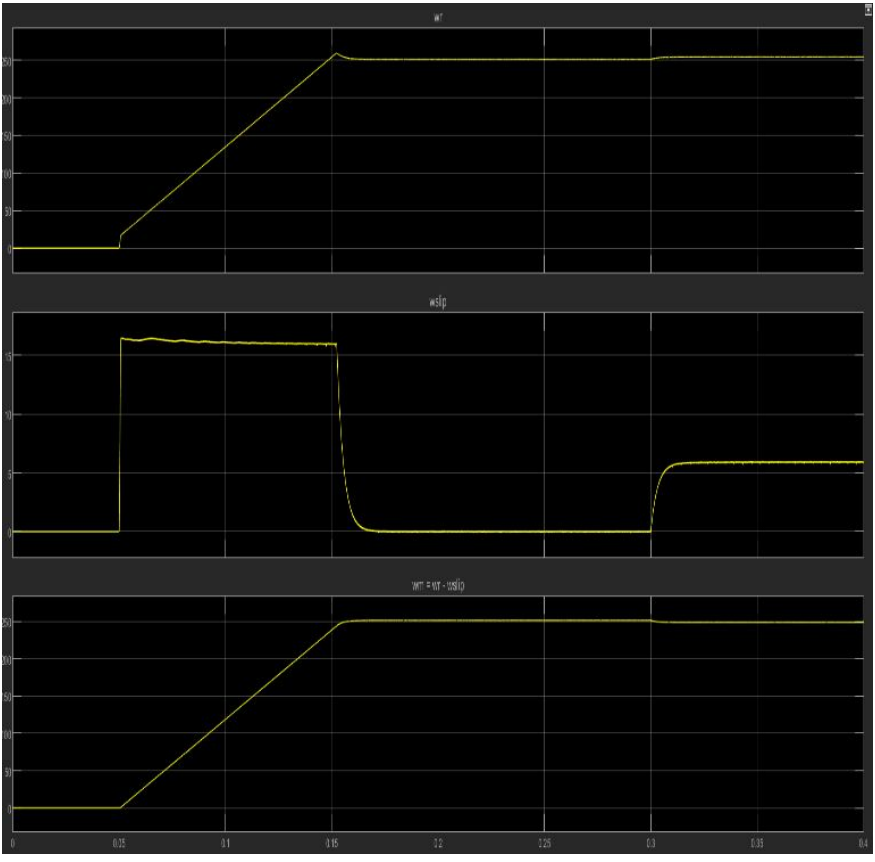

Figure 6: Results at Speed Estimator - Rotor speed, Slip speed and Machine speed.

From the modeling of speed estimator it is clear that the machine speed is the difference between the rotor speed and the slip speed. Hence the rotor speed and slip speed are estimated to get the machine speed which is fed back to DTC controller.

\section{CONCLUSION}

In this paper, a new direct torque control method is presented. The features of the proposed direct torque control method include providing constant inverter switching frequency and significantly reducing the torque and speed ripple. The Speed Estimator is used to estimate the speed of the machine and the estimated speed is fed back to the DTC controller by sing PI controllers. Various transformation techniques are involved to model the induction motor Electrical and Mechanical. The speed of the Induction machine can be controlled directly by using torque or stator flux in the proposed model and the simulation results are explained very clearly.

\section{REFERENCES}

1. I. Takahashi and Y. Ohmori, "High-performance direct torque control of induction motor," IEEE Trans. Ind. Appl., vol. 25, no. 2, pp. 257-264,1989.

2. T. G. Habetler, F. Profumo, M. Pastorelli, and L. M. Tolbert, "Direct torque control of induction machines using space vector modulation, "IEEE Trans. Ind. Appl.,vol.28, no.5, pp. 1045-1053,1992.

3. M.Depenbrock, "Direct-self control of inverter-fed induction machine," IEEE Trans.PowerElectrons, vol.3,no.4,pp.420-429,198 8.
4. Direct self control for high dynamics performance of inverterfeeda.c.machines,"ETZArchiv.,vol.7,no.7,p p.211-218,1985.

5. "Direct-self control of the flux and rotary moment of a rotary-fieldmachine,'USPatent4678248,1987.

6. P. Tiitinen, "The next generation motor control method, DTC direct torque control,"in Proceedings of the IEEE Intl.Conf. on Power Elec-tronics, Drives, and Energy Systems for Industrial Growth, 1996, pp.37-43.

7. J. N. Nash, "Direct torque control, induction motor vector control without an encoder,'IEEE Trans.Ind.Appl.,vol.33,no.2,pp.333-341,1997.

8. T.Noguchi, M.Yamamoto, S.Kondo,and I.Takashi,"High frequency switching operation of PWM inverter for direct torque control of induc-tion motor,"in Conference Record IEEE IAS Annual Meeting,1997,pp.775-780.

9. M. P. Kazmierkowski and A. B. Kasprowicz, "Improved direct torque and flux vector control of PWM inverter-fed induction motor drives,"IEEETrans.Ind.Electron.,vol.42, no.4, pp.344-349, 1995.

10. D. Casadei, G. Grandi, G. Serra, and A. Tani, "Switching strategies indirect torque control of induction machines," in Proc. of the Internal Conference on Electrical Machines(ICEM), 1994,pp.204-209.

11. K. B. Kumar, A. Bhanuchandar and C. Mahesh, "A Novel Control Scheme for Symmetric Seven Level Reduced Device Count Multi-Level DC Link (MLDCL) Inverter," 2021 International Conference on Sustainable Energy and Future Electric Transportation (SEFET), 2021, pp. 1-4, doi: 10.1109/SeFet48154.2021.9375714.

12. Kumar, Kasoju Bharath, Dongari Vamshy, and Mahesh Chanda. "A Novel Three phase Three Wire UPQC (Unified Power Quality Conditioner) Configuration using Ten Switch Topology for linear RL loads." IJITEE, Volume 10, Issue 4 DOI: 10.35940/ijitee.D8458.0210421

13.G.Buja, D.Casadei, and G.Serra,"Direct stator flux and torque control of an induction motor: Theoretical analysis and experimental results,"in Proceedings of the IECON '98, vol.1, 1998,pp.T50-T64. 